\title{
Caracterização de cadeias de suprimentos: uma aplicação do conceito de redes de empresas na região têxtil de Americana (SP)
}

Marcos de Carvalho Dias marcos.dias@fatec.sp.gov.br Faculdade de Tecnologia (Fatec), Americana, São Paulo, Brasil

\begin{abstract}
RESUMO
A indústria têxtil brasileira tem passado por transformações em relação a sua forma de organização da produção e de comercialização, principalmente após a abertura comercial realizada no início dos anos 90 . Estas rápidas transformações resultaram em sérias consequências para esta indústria, como o fechamento de muitas empresas e modificações nas relações entre os membros da cadeia de suprimentos têxtil em diversas regiões, como a região têxtil de Americana (SP), um dos maiores polos produtores e tecidos planos sintéticos do país. Assim, o objetivo desta pesquisa foi mapear e analisar a dinâmica e as características de cadeias de suprimentos das empresas têxteis nesta região , a partir das dimensões propostas na abordagem de análise de redes de empresas (centralidade, densidade, intermediação e proximidade). Para isso foi feita uma sondagem ou survey, baseada num questionário simples com questões diretas sobre as relações das principais empresas com fornecedores e clientes. Em seguida foi utilizada como ferramenta a metodologia de análise de redes. Os resultados obtidos permitiram observar que a pesquisa baseada na abordagem da teoria de análise de redes ajudou a entender as principais características dessa cadeia analisada, e que confirmaram algumas condições da dinâmica competitiva observados em pesquisas anteriores por esse autor, como pouca cooperação e proximidade entre componentes da cadeia, aumento do grau de internacionalização de algumas empresas e do grau de heterogeneidade nas empresas componentes do aglomerado têxtil da região.
\end{abstract}

PALAVRAS-CHAVE: Indústria Têxtil. Cadeia de Suprimentos. Redes de Empresas. 


\section{INTRODUÇÃO}

A indústria têxtil brasileira passou por importantes transformações nas últimas duas décadas, notadamente a partir do início da década de 90 , com o advento da abertura comercial realizada pelo governo federal (governo Collor) com o objetivo de promover a maior entrada de produtos com melhor qualidade, e assim aumentar a competitividade dos bens produzidos internamente.

Esse mecanismo provocou nesta indústria o aumento da competição interna com produtores dos países asiáticos, que inseriam no mercado nacional de tecidos e fios mais baratos que os produzidos internamente, o que provocou a redução do número de produtores nacionais e aumento do desemprego no setor.

As empresas têxteis que se mantiveram no mercado, passaram a adotar novas tecnologias de produção, como novas máquinas e equipamentos, bem como novos métodos produtivos.

No caso da indústria têxtil da região de Americana (SP), uma das principais regiões produtoras de tecidos planos sintéticos do país, este fato tem sido percebido pelas transformações na forma de organização das empresas da região, como alterações nas relações de produção internas e com fornecedores e clientes.

E é a partir destas transformações que surge o problema de pesquisa que originou este projeto: quais são as atuais características e forma de organização das principais cadeias de suprimentos das empresas têxteis na região de Americana?

Para responder a tal problema, esta pesquisa proposta teve por objetivo mapear e analisar a dinâmica e as características de algumas cadeias na região.

Para isso foi feita inicialmente uma revisão bibliográfica sobre os temas relacionados à pesquisa, como cadeias de suprimentos e rede de empresas. Em seguida, com o objetivo de mapear algumas cadeias foi utilizado como instrumental metodológico a sondagem ou survey, baseada num questionário simples com questões diretas sobre as relações das principais empresas com fornecedores e clientes. Em seguida foi utilizada como ferramenta de análise destas relações a metodologia de análise de redes.

Esta pesquisa é justificada pela importância histórica da indústria têxtil na região de Americana, pois representa a atividade produtiva em torno da qual as cidades da região se desenvolveram. Além disso, tal segmento produtivo possui importância econômica, por ser uma das principais atividades responsáveis pela geração de emprego e renda nestas cidades.

Assim sendo, a realização de estudos que abordem a dinâmica e a organização desta indústria na região representa uma forma de contribuição para o debate sobre os caminhos a serem tomados por esta indústria no futuro, bem como para a elaboração de políticas públicas que direcionem este caminho.

Quanto à abordagem, a pesquisa foi essencialmente qualitativa, pois buscou o aprofundamento da compreensão da realidade de um grupo específico: as cadeias de suprimentos existentes nas indústrias têxteis da região de Americana. Com isso, a pesquisa buscou produzir informações aprofundadas e ilustrativas sobre esta realidade, centradas na compreensão e explicação das relações entre 
as empresas.

Para a elaboração do estudo foi utilizado um roteiro de questões prédefinido, com questões objetivas, que permitam obter informações sobre as ligações das empresas com outros agentes da cadeia. Além destas questões, constou no roteiro informações sobre as empresas pesquisadas, como razão social, número de trabalhadores, tipo de produto, etc. Esta etapa da pesquisa foi realizada por meio de correio eletrônico, ligações telefônicas ou visitas pessoais às empresas.

Após a obtenção das informações das empresas pesquisadas, os dados foram inseridos em um software utilizado para análise de redes, o UCINET 6, que permitiu a geração de gráficos e informações sobre as relações estabelecidas entre as empresas pesquisadas, possibilitando assim a identificação das cadeias existentes e suas características, como densidade, centralidade, intermediação, etc.

Este software, disponível gratuitamente no site do desenvolvedor em sua versão básica para testes (o suficiente para a realização desta pesquisa), funciona no sistema operacional Windows e requer configurações básicas para sua instalação. Para sua utilização é necessário conhecimentos básicos em Excel, como inserção de dados em tabelas e geração de gráficos equadros.

As instruções quanto à forma de operacionalização e de análise dos resultados obtidos estão contidos num manual elaborado por Alejandro e Norman (2005), em que são abordadas as principais características e forma de utilização deste software.

Tal pesquisa foi centrada nas cadeias de suprimentos das empresas têxteis na região de Americana, considerando suas principais características a partir das dimensões propostas na abordagem de análise de redes de empresas (centralidade, densidade, intermediação e proximidade).

\section{O CONCEITO DE CADEIAS DE SUPRIMENTOS}

Os processos de produção e comercialização de uma empresa não estão somente circunscritos aos seus limites, mas se inicia e termina fora dela com a escolha criteriosa dos parceiros externos (fornecedores e clientes) que irão contribuir com as etapas de produção e distribuição dos bens e serviços produzidos.

Por isso, muitas empresas buscam frequentemente se organizarem em redes integradas para realizarem de forma ágil e eficiente os fluxos de materiais e informações, desde os fornecedores até os consumidores finais, controlando-os de forma sincronizada (BALLOU, 2010).

Dentre as organizações em rede de empresas, destaca-se a formação de uma cadeia integrada de empresas autônomas e semi-autônomas responsáveis pela produção e distribuição de um bem ou serviço ao cliente final objetiva controlar os referidos fluxos visando obter benefícios em termos de velocidade, confiabilidade, flexibilidade, custos e qualidade em relação ao controle interno dos fluxos (SLACK et al.,, 2010).

Esta forma de organização de empresas em redes é denominada cadeia de 
suprimentos, e caracteriza-se como sendo uma ferramenta utilizada em processos produtivos com o objetivo de coordenar o fluxo e armazenagem de materiais e informações durante todo o processo.

De forma geral, uma única empresa não possui mecanismo de controle da totalidade do fluxo de materiais e serviços envolvidos em todos os processos da cadeia. Assim sendo, as empresas devem assegurar o suprimento de cada segmento, de forma que todas as empresas ou segmentos componentes tirem proveito das vantagens advindas da relação entre estas na cadeia.

\section{DEFININDO CADEIAS DE SUPRIMENTOS}

Os temas abordados pelas cadeias de suprimento refletem os fenômenos decorrentes da economia internacional durante a segunda metade do século XX. Assim sendo, o mesmo fenômeno é documentado e pesquisado a partir de vários campos, resultando em vários termos que apontam fundamentalmente para a mesma realidade. No entanto, esses termos incorporam perspectivas de seus respectivos campos para caracterizar esta nova realidade.

As cadeias de suprimentos surgiram quando as questões relacionadas ao fluxo de materiais foram introduzidas pela primeira vez. Desde a década de 1990, no entanto, o termo mostrou um aumento exponencial de popularidade, juntamente com o conceito de gestão da cadeia de suprimento, introduzido por consultores na década de 1980, conforme Arshinder e Deshmukh 2008; Chen e Paulraj 2004. Entre suas muitas origens, Chen e Paulraj (2004) apontam para cinco, em particular, ao explicar esta tendência:

a) a revolução da qualidade;

b) noções de gestão de materiais e logística integrada;

c) um interesse crescente nos mercados e redes industriais;

d) a noção de maior foco;

d) influentes estudos específicos da indústria.

O termo "cadeia de suprimento", em contraste com a "cadeia de valor", permaneceu um termo relativamente unificado. No entanto, tem sido confusamente associado com várias definições em seu uso. Comum entre essas definições está a existência de uma estrutura de entrada-saída que abrange as atividades de valor agregado (GEREFFI et al., 2001).

Os esforços para investigar o fenômeno crescente da cadeia de suprimentos vieram de uma variedade de disciplinas como organização industrial, custos, economia, sociologia institucional e dinâmica de sistemas, entre outros (CROOM, ROMANO e GIANNAKIS, 2000; TANK, 2001; MELO, NÍQUEL e SALDANHA-DAGAMA, 2009).

Como resultado, uma grande variedade de termos relacionados ao conceito de cadeia de suprimentos também surgiu nas últimas décadas, e que podem ser encontradas em discussões entre acadêmicos, consultores ou gestores (CROOM, ROMANO e GIANNAKIS, 2000).

Por isso, o conceito de cadeia de suprimentos tem sido definido por diversos autores, porém com significados e abrangências muito próximas entre si. 
Autores como Lee (2000), Slack et al. (2010), Christopher (1999), Mentzer et al. (2001), Ballou (2010) e Jacobs e Chase (2015), dentre outros, buscaram definir o conceito de cadeia de suprimentos a partir de aspectos diversos. O quadro abaixo apresenta algumas das principais definições abordadas por estes autores.

Quadro 1 - A definição do conceito de cadeia de suprimentos

\begin{tabular}{|c|c|}
\hline Lee (1993) & $\begin{array}{l}\text { Rede de trabalho para as funções de busca de } \\
\text { materiais, sua transformação e distribuição. }\end{array}$ \\
\hline Quinn (1997) & $\begin{array}{l}\text { Atividades associadas com o movimento de } \\
\text { bens desde o estágio de matéria prima até o } \\
\text { usuário final. }\end{array}$ \\
\hline Lumus e Albert (1997) & Rede de entidades na qual o material flui. \\
\hline Christopher (1999) & $\begin{array}{l}\text { Rede de organizações que estão envolvidas } \\
\text { através de ligações a jusante (downstream) e a } \\
\text { montante (upstream) nos diferentes processos } \\
\text { que produzem valor. }\end{array}$ \\
\hline Lambert et al. (1998) & $\begin{array}{l}\text { Cadeia de múltiplos negócios, não apenas uma } \\
\text { cadeia de negócios de relacionamentos "um a } \\
\text { um". }\end{array}$ \\
\hline Mentzer et al. (2001) & $\begin{array}{l}\text { Um conjunto de três ou mais entidades } \\
\text { envolvidas nos fluxos dos produtos desde a } \\
\text { fonte primaria até o cliente final }\end{array}$ \\
\hline Slack et al. (2010), & $\begin{array}{l}\text { Todas as operações que fazem parte de uma } \\
\text { rede maior, interconectada com outras } \\
\text { operações, incluindo os fornecedores, os } \\
\text { clientes, os fornecedores dos fornecedores, os } \\
\text { clientes dos clientes e assim por diante. Neste } \\
\text { caso a cadeia de suprimento compreende } \\
\text { uma sequência de unidades produtivas } \\
\text { dentro da rede de suprimentos de uma } \\
\text { organização. }\end{array}$ \\
\hline Pires (2004) & $\begin{array}{l}\text { De modo geral, uma cadeia de suprimento é } \\
\text { uma rede de companhias autônomas, ou semi- } \\
\text { autônomas, responsáveis pela obtenção, } \\
\text { produção e liberação de um determinado } \\
\text { produto e ou serviço ao cliente final. }\end{array}$ \\
\hline Gaither e Frazier (2001) & $\begin{array}{l}\text { A forma que os materiais fluem através de } \\
\text { diferentes organizações, iniciando com as } \\
\text { matérias-primas recebidas dos fornecedores e } \\
\text { encerrando com produtos acabados entregues } \\
\text { ao consumidor final. }\end{array}$ \\
\hline Ballou (2010) & $\begin{array}{l}\text { Um conjunto de atividades funcionais } \\
\text { (transporte, controle de estoques, etc.) que se } \\
\text { repetem inúmeras vezes ao longo do canal }\end{array}$ \\
\hline
\end{tabular}




\begin{tabular}{|l|l|}
\hline & $\begin{array}{l}\text { pelo qual matérias-primas vão sendo } \\
\text { convertidas em produtos acabados, aos quais } \\
\text { se agrega valor ao consumidor. }\end{array}$ \\
\hline Jacobs e Chase (2015) & $\begin{array}{l}\text { A set of approaches utilized to efficiently } \\
\text { integrate suppliers manufacturers, } \\
\text { warehouses, and stores, so that } \\
\text { merchandise is produced and distributed } \\
\text { at the right quantities, to the right } \\
\text { locations, and at the right time, in order } \\
\text { to minimize system wide }\end{array}$ \\
\hline Supply Chain Council (2013) & $\begin{array}{l}\text { Starting with unprocessed raw materials } \\
\text { and ending with the final customer using } \\
\text { the finished goods, the supply chain links } \\
\text { many companies together. The material } \\
\text { and informational interchanges in the } \\
\text { logistical process stretching from } \\
\text { acquisition of raw materials to delivery of } \\
\text { finished products to the end user. All } \\
\text { vendors, service providers and customers } \\
\text { are links in the supply chain. }\end{array}$ \\
\hline
\end{tabular}

Fonte: Autoria própria a partir de diversos autores (2017)

De forma geral trata-se, portanto, da integração de todos os componentes desta cadeia, ou seja: fornecedores, fabricantes, armazéns e lojas, no momento em que a mercadoria é produzida e distribuída em determinadas quantidades, e enviadas para os locais certos e na hora certa, a fim de minimizar os custos de todo o sistema, atendendo requisitos de nível de serviço satisfatórios.

Assim, tal conceito se refere ao conjunto de organizações interdependentes que atuam de forma conjunta para realizar o controle e a gestão do fluxo de bens e serviços desde sua origem até a entrega final ao consumidor, visando a satisfação deste último no menor custo possível.

Figura 1- Cadeia de suprimentos convencional

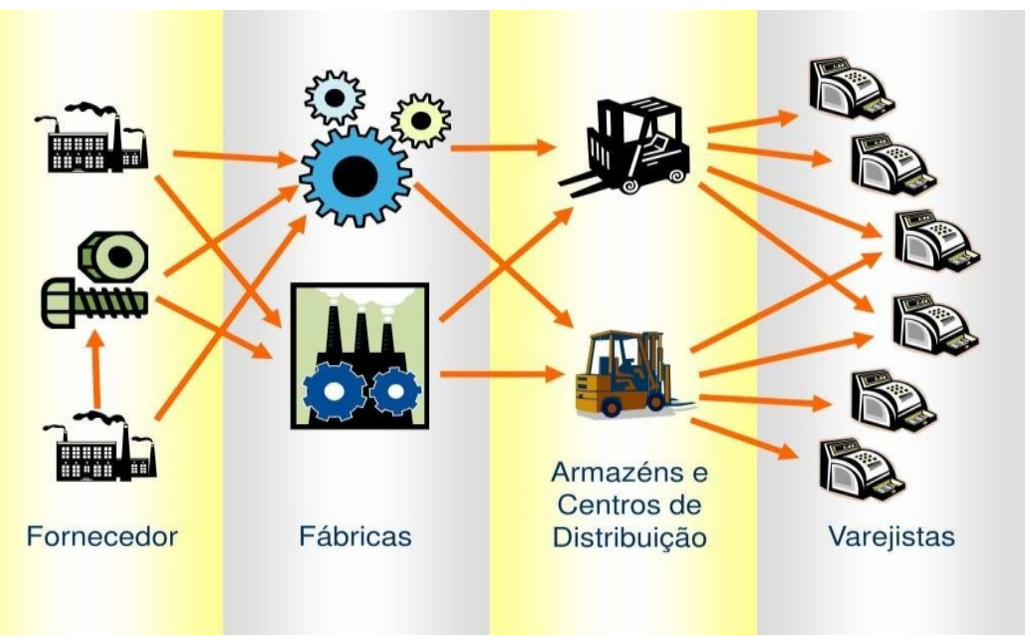

Fonte: extraído de https://scmsi.wordpress.com/ 
Para estes autores o objetivo específico da cadeia de suprimentos é permitir a integração de fornecedores, fabricantes, distribuidores e comerciantes de maneira alinhada. Que pode formar um complexo empresarial virtual, cujo foco é a obtenção de vantagens competitivas em relação aos concorrentes, por meio do melhor atendimento ao consumidor.

Por isso a competição não ocorre mais entre os membros de uma única cadeia, mas entre cadeias que produzem o mesmo bem ou serviço.

Ao descrever uma cadeia de suprimento convencional, Chopra e Meindl (2010) dividem esta em etapas de acordo com o processo estabelecido durante a produção. Estas etapas são:

a) planejamento: que corresponde à necessidade de estabelecimento, pelas empresas componentes, de metas a serem atingidas a partir de critérios predeterminados, que objetivem a visão integrada e ampla do ambiente em que está inserida. Isso é feito por meio do desenvolvimento de canais de distribuição e de compras, planejamento de estoques, de produção e de distribuição, planejamento de demanda, entre outras ações.

b) compras: compreende o processo de aquisição de matérias-primas e insumos por meio da seleção criteriosa de fornecedores, estabelecimento de contratos de negociação. Na atuação da empresa em redes e cadeias, o processo de compra não se limita ao ato de aquisição e monitoramento, mas também do controle estratégico dos custos, qualidade e prazo de entrega dos produtos.

c) produção: é o processo pelo qual as matérias-primas e insumos são transformados em bens e serviços finais. Tais processos podem ser o de produção contínua (make to stock), sendo uma parte da produção armazenada para atender as oscilações do mercado, ou de produção por encomenda (make to order), sendo as matérias-primas e insumos armazenados, e utilizados quando ocorre o recebimento do pedido.

d) distribuição: corresponde a movimento do bem ou serviço do produtor ao consumidor final. Nesta etapa são realizadas ações como gestão e controle de estoque, manuseio de materiais ou produtos acabados, transporte, armazenagem, administração de pedidos, análises de locais e rede de distribuição, e objetivam basicamente a redução dos custos e aumento da competitividade do produto final.

Ao estudar a cadeia de suprimentos, encontra-se constantemente o desafio metodológico de definir fronteiras entre as muitas interconexões de uma rede. A definição de Mentzer et. al. (2001) é propositadamente ampla para permitir que muitos atores possam existir entre a empresa e o consumidor final.

Enquanto as primeiras concepções da cadeia de suprimentos eram focadas no fluxo de bens de fornecedor para fabricante, distribuidor e usuário final, as cadeias de suprimento são agora reconhecidas como cobrindo a fonte de suprimento de fornecimento mais antigo ao consumo final (COOPER, LAMBERT e PAGH, 1997). Além disso, Mentzer et al.(2001) salientam que qualquer organização pode fazer parte de numerosas cadeias de abastecimento.

Estas tipologias classificam as cadeias de suprimento de acordo com o escopo organizacional, de acordo com graus de separação da empresa, sendo divididas em cadeia de suprimentos direta, estendida ou final. Uma cadeia de suprimento 
direta engloba a empresa focal e seus fornecedores e clientes imediatos. Uma cadeia de suprimento final inclui todas as organizações envolvidas a montante e a jusante em relação à empresa focal até que as cadeias de suprimento sejam alcançadas. Qualquer coisa entre a cadeia de suprimento direta e a cadeia de suprimento final no escopo pode ser referida como uma cadeia de suprimentos estendida (MENTZER et al., 2001).

\section{A EVOLUÇÃO DO CONCEITO}

Os primeiros profissionais dedicados às operações de distribuição física de mercadorias surgiram durante as décadas de 60 e 70 em diversos países da Europa e também nos Estados Unidos. A partir disso a gestão da distribuição física de mercadorias passou a ser vista como uma atividade crítica par a competitividade das empresas no mercado. Para atingir tal competitividade as empresas passaram a centrar a atenção em três aspectos principais:

a) cumprimento dos prazos de entrega;

b) eficiência na preparação dos produtos a serem enviados;

c) custos reduzidos.

Uma das principais preocupações na distribuição de bens e serviços das empresas aos consumidores finais ou intermediários era justamente o custo elevado desta operação. Na década de 70 estimava-se que os custos de distribuição variavam entre 10 a 40\% das receitas das empresas (STEVENS, 1989), mostrando que, apesar de uma possível eficiência na prestação destes serviços, seu custo era muito elevado.

Porém, com a especialização da gestão das operações neste período, ocorre uma redução nos custos destas, por meio da redução dos produtos armazenados para distribuição ao consumidor (GEPFERT, 1968).

A partir de então nota-se a necessidade da alteração da estrutura da gestão das empresas de forma geral, sendo necessária a distinção entre a gestão da empresa como um todo e gestão da distribuição dos bens e serviços produzidos, de forma específica.

Ainda na década de 70 tal separação ocorre nas empresas norte-americanas e europeias, sendo no início apenas em relação à distribuição de produtos perecíveis ou de elevada rotação, e posteriormente, com a percepção pelas empresas sobre os benefícios desta forma de gestão, a coordenação das atividades de distribuição passou a ser feita também com produtos duráveis e insumos produtivos (STEVENS, 1989).

Com isso, a gestão da distribuição de mercadorias passou a estabelecer níveis de desempenho e de custos dos serviços prestados pelas empresas, e as diversas atividades de distribuição (transporte, armazenamento, estocagem de mercadorias, entre outros), passaram a ser gerenciadas de forma integrada.

Assim, de uma visão centralizada na unidade fabril a gestão da distribuição permitiu a visualização da cadeia como um todo.

O avanço seguinte na gestão das cadeias de suprimento, ainda na década de 70, foi a percepção da necessidade de cooperação entre os diversos 
componentes com objetivo de reduzir ou eliminara duplicação das atividades realizadas na cadeia (HESKETT, 1977).

Dessa forma a logística dentro do sistema produtivo passou a ter uma maior importância como elemento estratégico de melhoria do deste sistema como um todo, e que poderia resultar no aumento da lucratividade de seus componentes.

Na década de 1980 a logística do serviço ao cliente, de forma específica, passou a ter importância e a ser considerada não somente o fornecimento do produto ao cliente, mas também o fluxo de informações que seguem este produto, como prazo de validade, especificações técnicas, formas de utilização, entre outras (SHAPIRO, 1984).

Este fato foi impulsionado pelo aumento do fornecimento de recursos de hardware e software com crescente capacidade de transmissão e tratamento de informações, e consequente redução de seus custos, o que resultou na generalização de seu uso nos sistemas produtivos e no ambiente empresarial.

A partir de então a gestão da distribuição passou a ter uma visão mais integrada da cadeia de abastecimento por meio da utilização dos recursos da tecnologia da informação, e que se consolidou no final da década de 80 (SHARMAN, 1984).

Atualmente, devido ao avanço da tecnologia da informação, o foco nas cadeias de suprimento tem se tornado um fator estratégico na gestão de empresas, e que permite que estas obtenham ganhos de produtividade resultantes da otimização das operações e das transações entre os membros da cadeia.

\section{OBJETIVO DA CADEIA DE SUPRIMENTOS}

Para Jacobs e Chase (2014) o objetivo específico das cadeias de suprimentos é permitir que sejam fornecidas as quantidades certas, no momento certo e pelos fornecedores certos, no menor custo possível. A integração de fornecedores, fabricantes, distribuidores e comerciantes de forma alinhada, formando um complexo empresarial virtual cujo foco é a obtenção de vantagens competitivas em relação aos concorrentes, por meio do melhor atendimento ao consumidor.

Já os objetivos derivados da gestão deste tipo de cadeia são: redução de estoques, elevação do nível (qualidade) dos serviços oferecidos aos clientes e constituição de vantagens competitivas de forma sustentável (COOPER e ELLRAM, 1993).

As cadeias de suprimentos convencionais englobam todas as atividades intra e interempresariais de um conjunto de empresas que compartilham as atividades de aquisição de insumos, produção de bens ou serviços, transporte e entrega destes aos clientes (MAIOUX, 2000).

Assim, uma cadeia de suprimento aparece como um processo contínuo que inclui as tradicionais funções atribuídas a cada elemento da cadeia isoladamente. Por meio a integração das atividades logísticas de cada elemento ao longo da cadeia de suprimento é possível evitar a ocorrência de duplicidade na cadeia, ou seja, dois ou mais elementos produzindo o mesmo tipo de bem ou serviço.

Porém Carvalho (1996) adverte que a cadeia de suprimento não se refere 
simplesmente a um conjunto de elementos que realizam atividades sequenciais entre si, mas sim de uma rede de produtores que buscam chegarao consumidor final com um bem ou serviço mais adequado às necessidades deste, ao mais baixo custo possível.

Por isso a competição não ocorre mais entre os membros de uma única cadeia, mas entre cadeias que produzem o mesmo bem ou serviço. Assim, a cadeia de suprimentos se caracteriza por uma rede que engloba todas as empresas que participam das diversas etapas de formação e comercialização de determinado produto ou serviço, que será entregue a um cliente final. Essas empresas podem ser de diversos tipos desempenhando diferentes responsabilidades na cadeia, desde a extração de um minério ou a manufatura de um componente, até a prestação de serviço logístico ou de vendas. Dependendo do seu produto, a companhia pode participar de diferentes cadeias. De acordo com Slack et al. (2010), a cadeia de suprimentos pode ser classificada em três níveis, rede total, rede imediata e rede interna, conforme apresentado na abaixo.

Figura 2 - Níveis das cadeias de suprimentos

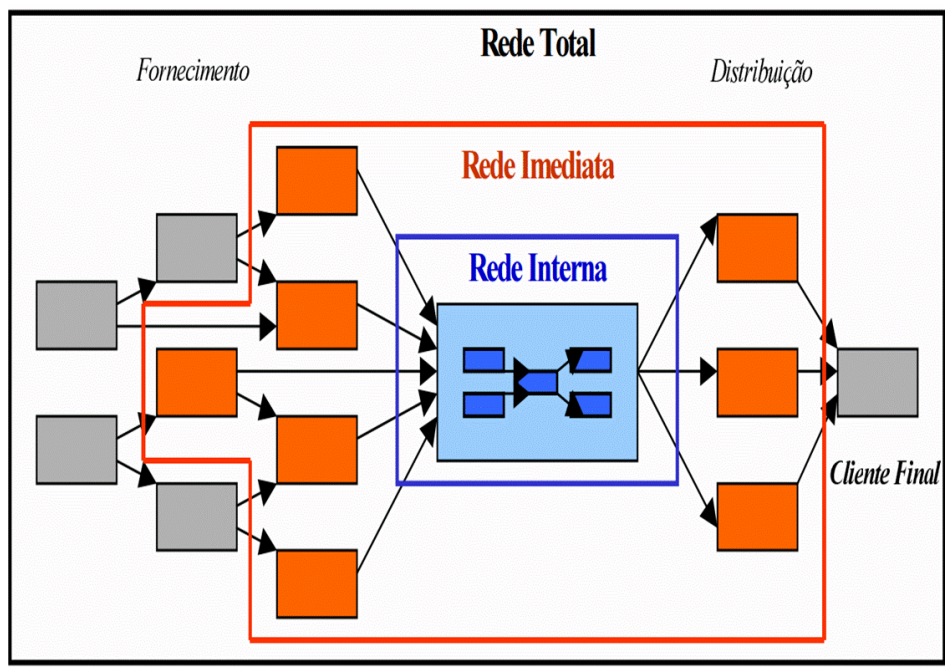

Fonte: Extraído de Slack e outros, 2010.

\section{A Cadeia de Suprimentos Têxtil}

No caso da indústria têxtil, a cadeia de suprimentos tradicional engloba a produção de fios e filamentos, manufaturados têxteis (tecidos ou malhas e tingimento ou estampagem), e pode ser dividida em segmentos industriais: fiação, tecelagem e acabamento (LA ROVERE, HASENCLEVER e MELO, 2001).

Estas atividades podem ser realizadas de maneira separada, ou seja, uma planta produtiva executa somente uma parte do processo (fiação, por exemplo), ou de forma integrada, em que uma planta executa várias etapas do processo (tecelagem e acabamento de tecidos).

Conforme Napoli (2007) a atuação de uma mesma firma em dois ou mais segmentos da cadeia produtiva pode ser explicada por problemas de fornecimento de matérias-primas, produtos ou serviços, e também por necessidades financeiras ou busca do aumento da competitividade, pois a 
integração produtiva pode resultar em redução nos custos devido aos ganhos obtidos com a maximização dos recursos disponíveis, como instalações e mãode-obra.

Algumas empresas optam pela especialização em determinada etapa produtiva da cadeia, devido à descontinuidade desta, que é a principal característica do processo produtivo têxtil. Nesse processo, cada produto elaborado em uma etapa pode ser utilizado como insumo para a etapa posterior (DIAS, 2014).

Por isso, o complexo produtivo têxtil representa o núcleo de uma cadeia produtiva à qual estão associados diversos outros segmentos de outros setores industriais, e que estão ligados à cadeia têxtil como fornecedores de matériasprimas, insumos e máquinas. Esse é o caso da indústria química, de máquinas e equipamentos, agroindústria, entre outras (CRUZ-MOREIRA, 2003).

Quanto às etapas que compõem a produção da cadeia têxtil, se caracterizam da seguinte forma:

- fiação: corresponde à produção de fios naturais, artificiais ou sintéticos, a partir da matéria-prima bruta. As fibras naturais são obtidas a partir do beneficiamento de produtos de origem animal (seda e lã), mineral (amianto) e vegetal (algodão, linho, juta, rami, etc). Já as fibras artificiais são obtidas por meio da regeneração da celulose natural, resultando em fibras como viscose, acetato e triacetato. As fibras sintéticas são derivadas de subprodutos do petróleo e dão origem a fios como poliéster, náilon, acrílico e polipropileno.

- tecelagem/malharia: compreende a produção de tecidos planos (tecelagem) ou malhas (malharia), que é resultado do entrelaçamento de conjuntos de fios, fornecidos pela fiação, realizados por um tear. Ao contrário da fiação, a tecelagem possibilita o ingresso de micro e pequenas empresas na indústria. 0 tear, por si só, é uma unidade produtiva independente, logo o aumento de produção é consequência da agregação de um maior número deteares.

- acabamento: corresponde a um conjunto de operações visando beneficiar o tecido cru, tornando-o confortável, durável e maleável, adequado ao uso pelo segmento de confecção. Tal processo não é uniforme, sendo variável de acordo com as características que se pretende obter do tecido, utilizando as várias formas de acabamento existentes por meio da realização de combinações entre as várias etapas que compõem o processo.

Figura 3 - Cadeia de suprimentos têxtil

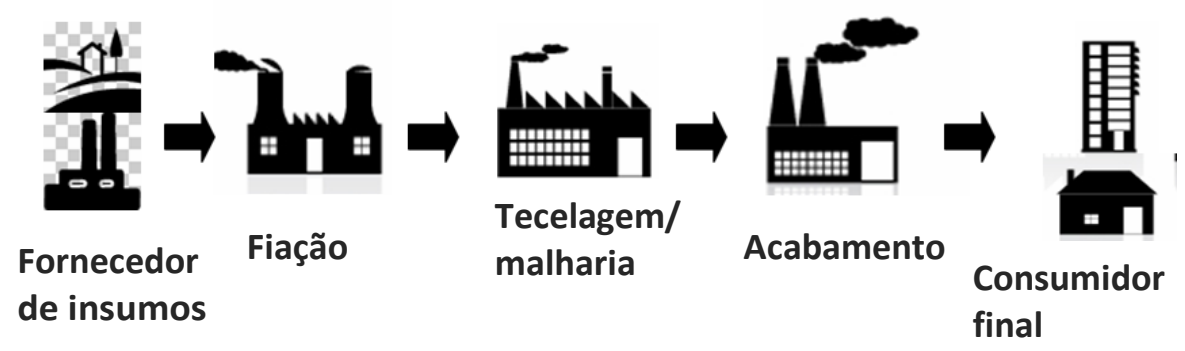

Fonte: elaboração própria 
Portanto, de forma geral, as empresas da cadeia têxtil são consideradas de baixa intensidade tecnológica e cuja tecnologia utilizada é bastante difundida no mercado, não havendo, portanto, fortes barreiras á entrada de novos concorrentes. Não existe entre as empresas líderes distanciamento tecnológico radical, e a competição ocorre por meio da redução dos preços em função da otimização da mão-de-obra e da matéria-prima (VIANA, BARROS NETO e AÑEZ, 2014).

Os principais agentes dessa cadeia são:

a) os fornecedores de matérias-primas, as fiações, que fornecem à cadeia fios de algodão naturais e sintéticos;

b) as tecelagens ou malharias, que produzem, a partir do fio, os tecidos ou malhas;

c) as empresas de beneficiamento, que são responsáveis pela limpeza e tingimento dos tecidos;

d) o mercado consumidor, que pode ser composto pelo consumidor final ou pelas confecções, que irão transformar o tecido ou malha em roupa pronta para o consumo.

Correa Neto e Pires (2003) apontam uma mudança ocorrida na cadeia têxtil no início da década de 90 no Brasil: um dos elos da cadeia têxtil, o comércio atacadista de tecidos, estava sendo descartado pelas empresas produtoras de tecidos, pois estas passaram a vender diretamente para os produtores de roupas, o que resultou numa redução de custos, para as confecções, de aproximadamente $20 \%$ do valor pago nos tecidos.

Com essa medida as tecelagens objetivaram a redução dos volumes vendidos às confecções, bem como a adoção de novas ações logísticas com o objetivo de reduzir os custos operacionais e aumentar a competitividade no mercado nacional.

\section{CARACTERIZAÇÃO DE CADEIAS DE SUPRIMENTOS: A ABORDAGEM DE REDES DE EMPRESAS}

A abordagem de redes de empresas tem sido utilizada em diversos trabalhos empíricos que buscam caracterizar as cadeias e suprimentos em diversos setores, como os trabalhos de Lima Filho et al. (2008), Ronqui et al. (2015), Barbosa e Sacomano (2011), Scavarda e Hamacher (2011), entre outros.

Isso porque a cadeia de suprimento corresponde a uma rede de empresas interligadas e que contribuem para as etapas de produção e comercialização de bens ou serviços a serem consumidos pelo mercado. Nesse sentido a abordagem de rede possui uma relação direta com o conceito de cadeia de suprimentos, pois representa uma ampla integração entre os agentes e demandam forte coordenação de atividades e processos (BARBOSA E SACOMANO, 2011; SCAVARDA E HAMACHER, 2011)

\section{O Conceito de Redes de Empresas}

Desta forma, a literatura apresenta uma ampla diversidade de aplicações e 
tipologias para o termo "rede", principalmente quando aplicado ao estudo das organizações. Brass et al. (2004) consideram que uma rede empresas corresponde a um conjunto de nós e laços que representam algum relacionamento ou a falta deste.

Na concepção de Rovan et al. (2007), uma rede de empresas é representada por um grupo composto por três ou mais organizações ligadas mutuamente de forma que facilitem a realização de um objetivo comum a elas, sendo estabelecidas relações não hierárquicas entre seus membros. Estes autores consideram também que os membros de uma rede podem ser conectados de várias formas, como informações, recursos materiais e financeiros, serviços, etc.

Para Lazzarini (2008), uma rede de empresas é definida como um conjunto de organizações que atuam numa mesma atividade produtiva, chamadas de agentes, que estabelecem relações (laços) entre si, podendo formar um aglomerado de empresas.

A relação entre as empresas componentes da rede pode ocorrer de formas distintas, conforme Tigre (2006):

a) redes hierarquizadas, que são coordenadas por uma empresa âncora, sendo os demais componentes um conjunto de fornecedores e clientes divididos em diferentes níveis, articulados em uma cadeia de suprimentos;

b) redes comandadas por produtores, em que uma empresa líder (produtora) “... atrai fornecedores especializados para assumir etapas ou funções na cadeia consideradas de menor valor ou que estejam fora de suas áreas de competência central" (TIGRE, 2006, pg. 221);

c) redes comandadas por compradores, em que grandes empresas varejistas comandam uma cadeia de fornecedores espalhados por diversos lugares;

d) redes comandadas por fornecedores de insumos, em que as empresas controlam a produção dos principais insumos da cadeia, e partir de então controlam todas as ações desta cadeia.

As redes de empresas são formadas inicialmente com o objetivo de reduzir os custos, incertezas e riscos inerentes ao mercado, organizando as atividades econômicas por meio da cooperação e coordenação das atividades empresariais. A formação de tais redes de empresas pode resultar em diferentes configurações, como as redes flexíveis de pequenas e médias empresas, os agrupamentos empresariais (clusters), redes virtuais de cooperação, ou ainda nas cadeias de suprimentos (LEON, 1998).

Conforme Ribault et al. (1995), uma rede de empresas é um modo de agrupamento empresarial destinado a favorecer a atividade das empresas pertencentes, sem que elas tenham, necessariamente, laços financeiros entre si.

Trata-se, portanto, de associações de natureza informal em que cada empresa é responsável pelo seu desenvolvimento no mercado. 
Para Tigre (2006), as redes de empresas representam uma forma eficiente de organização produtiva ao agregarem maior competência às empresas pertencentes, em relação às empresas que atuam de forma isolada, pois tais aglutinações permitem a obtenção de aspectos externos positivos, como redução de custos, aumento da eficiência técnica e possibilidade de ampliação dos mercados.

Nota-se, portanto, que diversos autores buscam definir, a partir de vários enfoques, o conceito de redes empresariais. No entanto, com citam Wasserman e Faust (1994) alguns conceitos são fundamentais para o entendimento destas redes. Tais elementos são:

- ator: que são os membros integrantes da rede, como os indivíduos, as empresas, os países, etc., e representam o foco principal do estudo das redes, cujo objetivo é entender como ocorrem as relações entre estes atores e as implicações destas relações;

- relação: que são os laços existentes entre dois ou mais atores darede;

- atributos: que são as características individuais de cada ator componente da rede;

- laços: que são as formas pelas quais os atores da rede se relacionam;

- díade: que corresponde a uma ligação entre dois membros de umarede;

- tríade: que representa a possível ligação entre três atores de uma rede e as implicações das ligações entre eles;

- subgrupo: é representado por um conjunto de atores e todos os laços existentes entre eles;

- clique: é um subgrupo de atores totalmente conectados;

- grupo: é um conjunto com todos os atores conectados entre si;

- rede: conjunto finito de atores e as relações entre eles.

A caracterização deste grupo de empresas em rede (como as cadeias de suprimentos) ocorre por da análise das relações entre estes agentes, das estruturas destas relações e como a posição destes agentes na cadeia pode influenciar o comportamento e o desempenho da cadeia como um todo.

Conforme Wasserman e Faust (1994) esta análise é feita com base nas dimensões descritivas da rede ou cadeia. Esta dimensão considera os seguintes aspectos:

a) centralidade, que corresponde a importância que um agente ou empresa possui dependendo do número de conexões, e quanto maior as conexões com outros agentes, maior a importância e a centralidade deste agente.

b) densidade corresponde a quantidade de ligações que o agente possui em relação ao total de ligações possíveis com todos os outros agentes, direta ou indiretamente. Isso significa que se todos os agentes da rede ou empresas da 
cadeia estabelecerem relações entre si, a densidade é a máxima possível.

c) alcance ou coesão da rede, que corresponde ao número máximo de relações diretas entre os agentes da rede ou cadeia de empresas, e quanto maior for o número destas relações, maior será a coesão desta.

d) intermediação entre os agentes, que corresponde ao número de agentes que são intermediários para a ligação com agentes distantes geograficamente da rede, ou que estão fora dela.

e) proximidade ou distância geodésica, que representa a localização geográfica entre os atores, considerando o afastamento ou proximidade de um agente ou empresa relação aos demais.

Figura 04 -Exemplos de redes
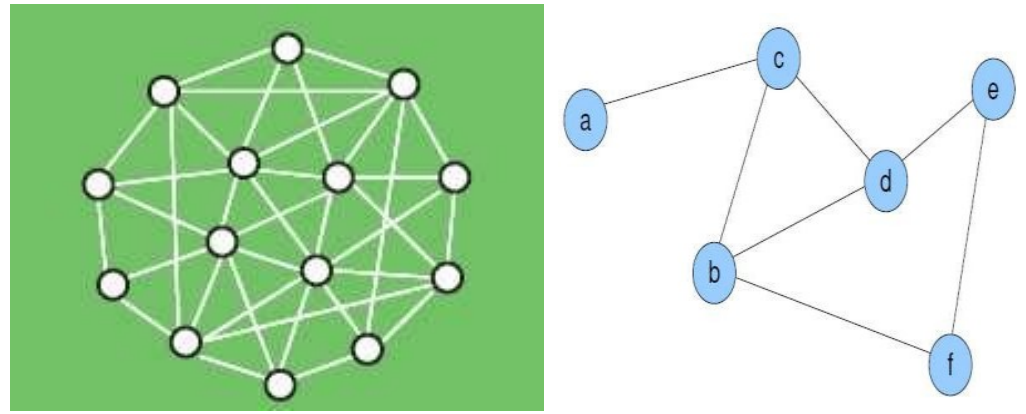

Fonte: Elaboração própria a partir de Magdaleno et al., 2010.

Assim, as redes podem analisadas a partir de suas propriedades e características, com o objetivo de caracterizá-las e dimensioná-las quanto a sua importância e desempenho.

Esta análise geralmente é feita com a utilização de softwares específicos para esse fim (UCINET, PAJEK for Windows, Netminer, etc), e que representam, conforme Borgatti et al. (2002), um meio de obter maior velocidade na realização da análise e construção de gráficos e relatórios mais precisos. Um exemplo deste tipo de software é o utilizado nesta pesquisa, o UCINET, que possibilita a caracterização das estruturas das redes de empresas, permitindo desenvolver um sistema de informações que viabilize a tomada de decisões organizacionais. Assim, é possível mapear a estrutura das redes organizacionais em momentos diferentes, observando mudanças nesta estrutura. Após a coleta dos dados relacionados aos atores da rede, a utilização de um software para a análise dos dados possibilitará a construção das matrizes sociométricas e a visualização final das redes constituídas.

Por fim, segundo Knoke e Kuklinsky (1982), 
"A tarefa do analista de redes é utilizar as relações para mapear os atores concretos em posições latentes. Nesse processo, a complexidade da rede é tipicamente simplificada ao reduzir um grande número de $(N)$ atores para números menores de $(\mathrm{M})$ posições, desde que esses atores empíricos ocupem a mesma posição (ex. médicos, enfermeiras e pacientes em um hospital)." (p.19)

\section{A PESQUISA NAS EMPRESAS}

A partir das considerações feitas sobre os conceitos de cadeia de suprimentos e redes de empresas, são apresentados a seguir os principais aspectos da aplicação desses conceitos em uma cadeia de empresas têxteis .

\section{LOCALIZAÇÃO DS EMPRESAS PESQUISADAS}

As empresas que fizeram parte desta pesquisa estão localizadas na região conhecida como "região têxtil de Americana", que corresponde a um conjunto de municípios interligados, localizado a Leste do Estado de São Paulo e distante aproximadamente $120 \mathrm{~km}$ da capital, entre os municípios de Piracicaba e Campinas. Estes municípios são: Americana, Santa Bárbara D'Oeste, Nova Odessa e Sumaré.

Esta região possuía em 2010 uma população de aproximadamente 683 mil habitantes em um território de aproximadamente $988 \mathrm{Km} 2$. Caracteriza-se por ser um importante pólo industrial do Estado, devido à quantidade e diversidade de empresas localizadas na região. Além da indústria têxtil, possui também importantes empresas da indústria automobilística, metal-mecânica, autopeças, borracha, química, entre outras (IBGE, 2018).

Em 2018 a região possuía 1712 indústrias têxteis, que compunham todos os segmentos da cadeia produtiva, empregando cerca de 27,5 mil trabalhadores, o que representava $14,43 \%$ do total de trabalhadores formais da região, e aproximadamente $5,25 \%$ do total de estabelecimentos, conforme informações do Ministério do Trabalho e Emprego (2018).

Isso mostra que o setor têxtil ainda possui grande importância na região como principal segmento produtivo da indústria de transformação, representando o principal segmento empregador de mão de obra da região.

\section{CARACTERÍSTICAS DAS EMPRESAS}

A amostra de empresas que compõem a pesquisa foi extraída de um universo de aproximadamente $\mathbf{3 0 0}$ empresas associadas ao Sindicato Patronal do setor na região (Sinditec), que constam numa lista fornecida por este. Tal amostra é composta por 12 empresas previamente selecionadas a partir do principal critério apontado no projeto: possuir mais de 100 funcionários, sendo classificada, portanto, como média ou grande empresa, conforme critérios de classificação do IBGE.

As principais características dessa amostra são descritas no quadro a seguir, porém convém ressaltar que, como algumas empresas não autorizaram a 
divulgação do nome, estes foram omitidos em todas as empresas pesquisadas:

Quadro 2 - Características das empresas pesquisadas

\begin{tabular}{|c|c|c|c|c|}
\hline Empresa & $\begin{array}{l}\text { Características } \\
\text { (localização; } \\
\text { número de } \\
\text { funcionários) }\end{array}$ & $\begin{array}{l}\text { Principal } \\
\text { produto }\end{array}$ & Fornecedores & Clientes \\
\hline $\begin{array}{c}\text { Tecelagem } \\
01\end{array}$ & $\begin{array}{c}\text { Americana; } \\
232\end{array}$ & $\begin{array}{l}\text { Tecidos de } \\
\text { polyester }\end{array}$ & $\begin{array}{c}\text { Fiações } \\
\text { asiáticas (China, } \\
\text { Coréia do } \\
\text { Sul e Indonésia) }\end{array}$ & $\begin{array}{c}\text { Pequenas } \\
\text { Confecções } \\
\text { do } \\
\text { Sul do país }\end{array}$ \\
\hline $\begin{array}{c}\text { Tecelagem } \\
02\end{array}$ & $\begin{array}{l}\text { Nova Odessa; } \\
458\end{array}$ & $\begin{array}{l}\text { Fitas têxteis } \\
\text { de polyester. }\end{array}$ & $\begin{array}{c}\text { Fiações } \\
\text { asiáticas (China, } \\
\text { Coréia do } \\
\text { Sul e Indonésia) }\end{array}$ & $\begin{array}{l}\text { Atacadistas } \\
\text { de todo o } \\
\text { país }\end{array}$ \\
\hline $\begin{array}{c}\text { Tecelagem } \\
03\end{array}$ & $\begin{array}{l}\text { Nova Odessa; } \\
354\end{array}$ & $\begin{array}{l}\text { Tecidos de } \\
\text { algodão para } \\
\text { camisaria }\end{array}$ & $\begin{array}{l}\text { Fiação de } \\
\text { algodão de } \\
\text { São Carlos e } \\
\text { fiação de } \\
\text { sintéticos da } \\
\text { Ásia }\end{array}$ & $\begin{array}{c}\text { Confecções } \\
\text { no norte do } \\
\text { Paraná e } \\
\text { mercado } \\
\text { externo }\end{array}$ \\
\hline $\begin{array}{c}\text { Tecelagem } \\
04\end{array}$ & $\begin{array}{l}\text { Sta. Bárbara } \\
\text { d'Oeste; } \\
817\end{array}$ & $\begin{array}{c}\text { Tecidos denin } \\
\text { (jeans) }\end{array}$ & $\begin{array}{c}\text { Fiação de } \\
\text { algodão de } \\
\text { São Carlos, } \\
\text { fiações de } \\
\text { polyester da } \\
\text { Ásia e } \\
\text { fiações de } \\
\text { Elastano de } \\
\text { Paulínia. }\end{array}$ & $\begin{array}{l}\text { Confecções } \\
\text { em todo o } \\
\text { país, e } \\
\text { mercado } \\
\text { externo }\end{array}$ \\
\hline $\begin{array}{c}\text { Tecelagem } \\
05\end{array}$ & $\begin{array}{l}\text { Americana; } \\
529\end{array}$ & $\begin{array}{c}\text { Tecidos denin } \\
\text { (jeans) }\end{array}$ & $\begin{array}{c}\text { Fiação de } \\
\text { algodão de São } \\
\text { Carlos(SP) e no } \\
\text { Ceará }\end{array}$ & $\begin{array}{c}\text { Confecções } \\
\text { no norte do } \\
\text { Paraná e São } \\
\text { Paulo }\end{array}$ \\
\hline $\begin{array}{c}\text { Tecelagem } \\
06\end{array}$ & $\begin{array}{l}\text { Americana; } \\
238\end{array}$ & $\begin{array}{l}\text { Tecidos de } \\
\text { algodão }\end{array}$ & $\begin{array}{l}\text { Fiação de } \\
\text { algodão de } \\
\text { São Carlos }\end{array}$ & $\begin{array}{c}\text { Confecções } \\
\text { no norte do } \\
\text { Paraná e São } \\
\text { Paulo }\end{array}$ \\
\hline $\begin{array}{c}\text { Tecelagem } \\
07\end{array}$ & $\begin{array}{l}\text { Americana; } \\
173\end{array}$ & $\begin{array}{l}\text { Tecidos } \\
\text { sintéticos }\end{array}$ & Fiações asiáticas & $\begin{array}{c}\text { Confecções } \\
\text { em todo o } \\
\text { país }\end{array}$ \\
\hline $\begin{array}{c}\text { Tecelagem } \\
08\end{array}$ & $\begin{array}{l}\text { Americana; } \\
267\end{array}$ & $\begin{array}{l}\text { Tecidos de } \\
\text { acabamento } \\
\text { em geral }\end{array}$ & Fiações asiáticas & $\begin{array}{c}\text { Confecções } \\
\text { em todo o } \\
\text { país }\end{array}$ \\
\hline $\begin{array}{c}\text { Tecelagem } \\
09\end{array}$ & $\begin{array}{l}\text { Americana; } \\
156\end{array}$ & $\begin{array}{l}\text { Tecidos para } \\
\text { cortinas e } \\
\text { acabamentos }\end{array}$ & $\begin{array}{l}\text { Fiação de } \\
\text { algodão do } \\
\text { Ceará } \\
\text { e fiações } \\
\text { asiáticas } \\
\end{array}$ & $\begin{array}{l}\text { Atacadistas } \\
\text { de todo o } \\
\text { país }\end{array}$ \\
\hline
\end{tabular}




\begin{tabular}{|c|l|c|c|c|}
\hline $\begin{array}{c}\text { Tecelagem } \\
10\end{array}$ & $\begin{array}{l}\text { Americana; } \\
289\end{array}$ & $\begin{array}{c}\text { tecidos 100\% } \\
\text { poliamida, } \\
100 \% \\
\text { poliéster ou } \\
\text { mistos }\end{array}$ & $\begin{array}{c}\text { Fiação de } \\
\text { Elastano de } \\
\text { Paulínia; } \\
\text { fiação de } \\
\text { poliéster } \\
\text { asiática }\end{array}$ & $\begin{array}{c}\text { Confecções } \\
\text { em todo o } \\
\text { país }\end{array}$ \\
\hline $\begin{array}{c}\text { Tecelagem } \\
11\end{array}$ & $\begin{array}{l}\text { Sta. Bárbara } \\
\text { d'Oeste; } \\
217\end{array}$ & $\begin{array}{l}\text { Toalhas e } \\
\text { cortinas de } \\
\text { algodão }\end{array}$ & $\begin{array}{c}\text { Fiação de } \\
\text { algodão do } \\
\text { Ceará }\end{array}$ & $\begin{array}{c}\text { Atacadistas } \\
\text { de todo o } \\
\text { país }\end{array}$ \\
\hline $\begin{array}{c}\text { Tecelagem } \\
12\end{array}$ & $\begin{array}{l}\text { Sta. Bárbara } \\
\text { d'Oeste; }\end{array}$ & $\begin{array}{c}\text { Tecidos denin } \\
\text { (jeans) }\end{array}$ & $\begin{array}{c}\text { Fiações de } \\
\text { algodão do } \\
\text { Ceará e de São } \\
\text { Carlos/ Fiação } \\
\text { de Elastano de } \\
\text { Paulínia; fiações } \\
\text { asiáticas }\end{array}$ & $\begin{array}{c}\text { Confecções } \\
\text { de São Paulo, } \\
\text { norte do } \\
\text { Paraná; } \\
\text { mercado } \\
\text { externo, } \\
\text { principalmen } \\
\text { te }\end{array}$ \\
& & $\begin{array}{c}\text { Europa e } \\
\text { EUA. }\end{array}$ \\
\hline
\end{tabular}

Fonte: empresas pesquisadas

\section{CONFIGURAÇÃO DA CADEIA PESQUISADA}

A análise da cadeia da amostra foi feita, conforme mencionado

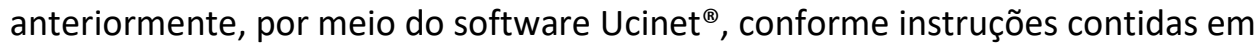
Alejandro e Norman (2005). Para isso, o primeiro passo foi a transformação dos atores em nomenclaturas para a constituição da matriz. Essa nomenclatura, constituída a partir das informações constantes na tabela anterior, é apresentada a seguir:

$$
\begin{aligned}
\mathrm{T} 1 & =\text { Tecelagem } 01 \\
\mathrm{~T} 2 & =\text { Tecelagem } 02 \\
\mathrm{~T} 3 & =\text { Tecelagem } 03 \\
\mathrm{~T} 4 & =\text { Tecelagem } 04 \\
\mathrm{~T} 5 & =\text { Tecelagem } 05 \\
\mathrm{~T} 6 & =\text { Tecelagem } 06 \\
\mathrm{~T} 7 & =\text { Tecelagem } 07 \\
\mathrm{~T} 8 & =\text { Tecelagem } 08 \\
\mathrm{~T} 9 & =\text { Tecelagem } 09 \\
\mathrm{~T} 10 & =\text { Tecelagem } 10 \\
\mathrm{~T} 11 & =\text { Tecelagem } 11 \\
\mathrm{~T} 12 & =\text { Tecelagem } 12
\end{aligned}
$$


F1= Fiações asiáticas (China, Coréia do Sul ou Indonésia)

F2 = Fiação de algodão Ceará

F3 = Fiação de algodão de São Carlos (SP)

F4 = Fiação de elastano de Paulínia (SP)

C1 = confecções de todo o país

$\mathrm{C} 2$ = confecções de SP

C3 = confecções do Sul do país (Paraná, Santa Catarina ou RS)

C4 = confecções do norte do Paraná

C5 $=$ atacadistas de todo o país $\mathrm{C} 6$ = mercado externo

A partir da construção da matriz, e da aplicação desta no programa NetDraw $^{\circledR}$, em que cada ator corresponde a um nó da cadeia, conforme apresentado a seguir:

Figura 5 - A cadeia de empresas pesquisada

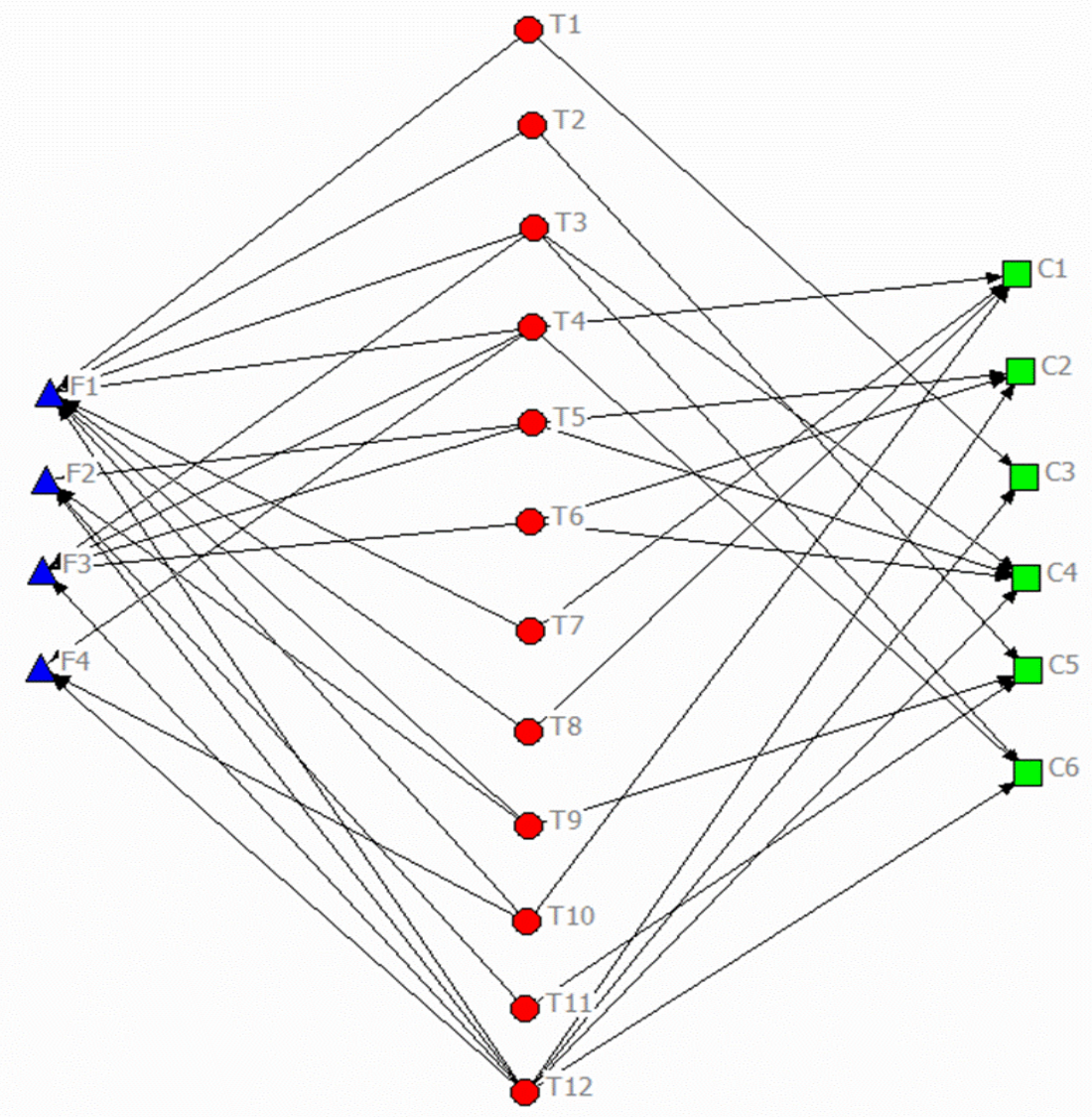

Fonte: Obtido a partir da utilização do NetDraw ${ }^{\circledR}$ 


\section{RESULTADOS OBTIDOS}

Nessa etapa serão apresentados os principais aspectos que caracterizam as cadeias pesquisadas, como sua densidade, grau de centralidade eproximidade.

a) Densidade:

O cálculo da densidade de uma rede ou cadeia é feito por meio de uma fórmula matemática que divide o número de relações existentes pelo número de relações possíveis, multiplicando o resultado por 100 , ou seja, $D=(R E / R P) x$ 100. O cálculo do total de relações possíveis é feito por meio da multiplicação do número total de nós pelo mesmo número menos um. Assim temos RP = NTN $x($ NTN -1$)$. As relações possíveis na cadeia analisada correspondem às relações entre as tecelagens ( $T^{\prime}$ 's) e seus fornecedores ( $\left.F^{\prime} s\right)$ e clientes $\left(C^{\prime} s\right)$. Assim temos 4 fornecedores e 6 clientes mencionados, num total de 10 nós. Portanto as relações possíveis são: $R P=10 \times 9=90$. Sendo as relações existentes entre as tecelagens e esses nós num total de 39 das 90 possíveis, temos a densidade como sendo: $D=(39 / 90) \times 100=43,33$, ou seja, tal densidade é de $43,33 \%$. Isso mostra que essa cadeia de empresas pesquisa possui pouca densidade ou densidade baixa, por ser seu percentual menor que $50 \%$, conforme Alejandro e Norman (2005).

b) Grau de centralidade:

O grau de centralidade corresponde ao número de interações entre os atores da rede, e é subdividido em grau de entrada e grau de saída, dependendo da direção do fluxo.

- $\quad$ grau de saída: corresponde ao número de interações que um ator específico possui com outros atores;

- $\quad$ grau de entrada: corresponde ao número de interações que os outros atores possuem com um ator específico.

$\mathrm{Na}$ análise da cadeia da amostra, apresentado na tabela a seguir, o grau de entrada aparece com a nomenclatura InDegree, e o de saída com a de OutDegree. As nomenclaturas NrmOutDeg e NrmInDeg representam o percentual de interações de saída e entrada d cada ator, respectivamente.

Figura 6 - Grau de centralidade da cadeia pesquisada

\begin{tabular}{|c|c|c|c|c|c|}
\hline & & OutDegree & InDegree & NrmoutDeg & NrmInDeg \\
\hline 12 & $\mathrm{~T} 12$ & 8.000 & 0.000 & 38.095 & 0.000 \\
\hline 4 & $\mathrm{~T} 4$ & 5.000 & 0.000 & 23.810 & 0.000 \\
\hline 3 & T3 & 4.000 & 0.000 & 19.048 & 0.000 \\
\hline 5 & T5 & 4.000 & 0.000 & 19.048 & 0.000 \\
\hline 6 & T6 & 3.000 & 0.000 & 14.286 & 0.000 \\
\hline 10 & T10 & 3.000 & 0.000 & 14.286 & 0.000 \\
\hline 9 & T9 & 3.000 & 0.000 & 14.286 & 0.000 \\
\hline 2 & T2 & 2.000 & 0.000 & 9.524 & 0.000 \\
\hline 7 & T7 & 2.000 & 0.000 & 9.524 & 0.000 \\
\hline 8 & T8 & 2.000 & 0.000 & 9.524 & 0.000 \\
\hline 11 & T11 & 2.000 & 0.000 & 9.524 & 0.000 \\
\hline 1 & $\mathrm{~T} 1$ & 2.000 & 0.000 & 9.524 & 0.000 \\
\hline $1 \overline{3}$ & $\mathrm{~F} 1$ & 0.000 & 9.000 & 0.000 & 42.857 \\
\hline 14 & $\mathrm{~F} 2$ & 0.000 & 4. 000 & 0.000 & 19.048 \\
\hline 15 & F3 & 0.000 & 5.000 & 0.000 & 23.810 \\
\hline 16 & F4 & 0.000 & 3.000 & 0.000 & 14.286 \\
\hline 17 & C1 & 0.000 & 4.000 & 0.000 & 19.048 \\
\hline 18 & C2 & 0.000 & 3.000 & 0.000 & 14.286 \\
\hline 19 & C3 & 0.000 & 2.000 & 0.000 & 9.524 \\
\hline 20 & $\mathrm{C} 4$ & 0.000 & 4.000 & 0.000 & 19.048 \\
\hline 21 & C5 & 0.000 & 3.000 & 0.000 & 14.2 \\
\hline & c6 & 0.000 & 3.000 & 0.000 & 14.286 \\
\hline
\end{tabular}

Fonte: Obtido a partir da utilização do Ucinet ${ }^{\circledR}$ 
c) Índice de centralização

O Índice de Centralização é uma situação em que o ator representa um papel central, pois está ligado a todos os outros nós da cadeia, e por isso todos eles deverão passar por este ator central para se ligarem uns aos outros.

Da mesma forma que no item anterior, este índice também apresenta um grau de saída (Outdegree) e de entrada (Indegree) . Na figura a seguir, nota-se que o grau de centralização de saída da rede, demonstrada pela expressão "Network Centralization - Indegree" é de 30,83\%, e a de entrada, demonstrada pela expressão "Network Centralization - Outdegree" é de 35,82\%.

Figura 7 - Índice de centralização da cadeia pesquisada

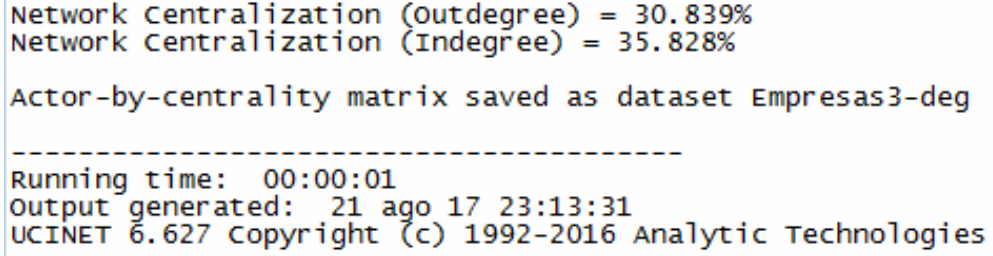

Fonte: Obtido a partir da utilização do Ucinet ${ }^{\circledR}$

Assim, conforme a tabela acima, obtida com a utilização do Ucinet ${ }^{\circledR}$, notase que a cadeia possui um baixo grau de centralização (abaixo de $50 \%$ ), não existindo, portanto, nenhum ator que centralize as ações da cadeia têxtil analisada.

d) Grau de proximidade:

Corresponde à capacidade de um nó em se ligar a todos os atores da rede, e é calculado por meio da somatória da distância de um ator em relação aos atores restantes (distância geodésica). Assim, cada ator possui uma distância em relação aos seus companheiros, ou seja, um valor que corresponde ao intervalo entre um ator em relação aos demais.

Na utilização do Ucinet $^{\circledR}$ são apresentados dois tipos de proximidade: a proximidade de entrada (InCloseness), que representa o número de atores com quem $o$ ator em questão se relaciona, e ao proximidade de saída (OutCloseness), que corresponde ao número de atores que se relacionam com o ator em questão (ALEJANDRO e NORMAN, 2005).

No caso da amostra analisada, os indicadores sobre o grau de proximidade mostram que o ator central, se considerarmos o grau de proximidade de entrada, é o F1, por possuir um grau de 7,692. Já se considerarmos a proximidade de saída, o principal ator é o T12, por possuir um grau de 7,143, conforme tabela a seguir. 
Figura 8 - Grau de proximidade da cadeia pesquisada

closeness centrality Measures

$\begin{array}{rrrrrr} & & & 1 & 2 & 3 \\ & & \text { inFarness } & \text { outFarness } & \text { incloseness } \\ 13 & \text { F1 } & 273.000 & 462.000 & 7.692 & 4.545 \\ 15 & \text { F3 } & 357.000 & 462.000 & 5.882 & 4.545 \\ 17 & \text { C1 } & 378.000 & 462.000 & 5.556 & 4.545 \\ 14 & \text { F2 } & 378.000 & 462.000 & 5.556 & 4.545 \\ 20 & \text { C4 } & 378.000 & 462.000 & 5.556 & 4.545 \\ 22 & \text { C6 } & 399.000 & 462.000 & 5.263 & 4.545 \\ 16 & \text { F4 } & 399.000 & 462.000 & 5.263 & 4.545 \\ 21 & \text { C5 } & 399.000 & 462.000 & 5.263 & 4.545 \\ 18 & \text { C2 } & 399.000 & 462.000 & 5.263 & 4.545 \\ 19 & \text { C3 } & 420.000 & 462.000 & 5.000 & 4.545 \\ 1 & \text { T1 } & 462.000 & 420.000 & 4.545 & 5.000 \\ 12 & \text { T12 } & 462.000 & 294.000 & 4.545 & 7.143 \\ 2 & \text { T2 } & 462.000 & 420.000 & 4.545 & 5.000 \\ 3 & \text { T3 } & 462.000 & 378.000 & 4.545 & 5.556 \\ 4 & \text { T4 } & 462.000 & 357.000 & 4.545 & 5.882 \\ 5 & \text { T5 } & 462.000 & 378.000 & 4.545 & 5.556 \\ 6 & \text { T6 } & 462.000 & 399.000 & 4.545 & 5.263 \\ 7 & \text { T7 } & 462.000 & 420.000 & 4.545 & 5.000 \\ 8 & \text { T8 } & 462.000 & 420.000 & 4.545 & 5.000 \\ 9 & \text { T9 } & 462.000 & 399.000 & 4.545 & 5.263 \\ 10 & \text { T10 } & 462.000 & 399.000 & 4.545 & 5.263 \\ 11 & \text { T11 } & 462.000 & 420.000 & 4.545 & 5.000\end{array}$

Fonte: Obtido a partir da utilização do Ucinet ${ }^{\circledast}$

\section{Análise dos Resultados}

A partir dos dados obtidos com a utilização das ferramentas Ucinet ${ }^{\circledast}$ e NetDraw $^{\circledR}$, com base nas informações coletados junto às empresas da amostra, que formam uma cadeia de suprimentos têxtil, pois compõem "... uma rede de companhias autônomas, ou semi-autônomas, responsáveis pela obtenção, produção e liberação de um determinado produto e ou serviço o cliente final" (PIRES, 2004), e “...que estão envolvidas através de ligações a jusante (downstream) e a montante (upstream) nos diferentes processos que produzem valor" (CHRISTOPHER, 1999).

Tais dados mostram que a cadeia pesquisada possui alguns aspectos específicos que são decorrentes da atual dinâmica competitiva da indústria têxtil brasileira: a) a dispersão dos produtores, pois estabelecem poucas relações de cooperação e de proximidade interempresariais; b) a internacionalização da cadeia, cujo fornecimento das matérias-primas principais é feito por empresas estrangeiras; c) a existência de algumas grandes empresas que atuam em mercados nacionais e internacionais, num setor dominado por pequenas emédias empresas regionais.

No primeiro caso, tal fato é comprovado pela baixa densidade da cadeia pesquisada, e que pode representar o comportamento de grande parte das empresas que compõem o setor produtivo têxtil de forma geral. Os dados demonstram que a densidade da cadeia pesquisada é de $43,33 \%$, o que representa um percentual abaixo do grau considerado mediano, que é de $50 \%$.

No segundo caso é ressaltada na cadeia têxtil pesquisada a existência de um ator central, o F1, que corresponde as empresa asiáticas fornecedores de fios para tecelagem, confirmado pelo grau de centralidade desse ator. Isso demonstra a importância e a intensidade da aquisição de matérias-primas dos 
produtores asiáticos, principalmente da China, Coréia do Sul e Indonésia, pelos produtores de tecidos da região pesquisada. Isso tem provocado a crescente internacionalização dessa cadeia, pois as empresas da região passaram a adquirir fios importados desses países, principalmente por causa do preço mais baixo que o dos produtores nacionais, provocando o encerramento das atividades das grandes fiações instaladas na região, a partir da década de 2010. Assim o aglomerado têxtil da região de Americana, que possuía até o fim dos anos 90 todas as etapas da cadeia têxtil instaladas na região (fiação, tecelagem, acabamento e confecções), perdeu um desses atores: os produtores de fios (DIAS, 2014).

Com isso a governança da cadeia têxtil regional, que até o início dos anos 2000 era estabelecida pelas empresas fornecedoras de matérias-primas nacionais (grandes fiações estabelecidas na região, e que encerram suas atividades nos últimos 5 anos), passou a ser estabelecida pelos grande varejistas internacionais, sediados nos países desenvolvidos.

No terceiro caso, tal fato é comprovado pela existência, na cadeia analisada, de outro ator importante, o T12, que corresponde a uma grande tecelagem estabelecida na região, com mais de 2 mil funcionários diretos, produtora de tecido jeans que é exportando para diversos países da Europa e também para os EUA. Essa é uma das únicas empresas da amostra, além de outras duas, que atende o mercado externo, sendo que as outras nove restantes atendem unicamente o mercado regional e nacional. $\mathrm{O}$ ator T12 se destaca na amostra pelo seu alto grau de centralidade, que é de 8 , sendo o restante com o grau de 5 ou inferior a isso.

\section{CONSIDERAÇ̃̃ES FINAIS}

Esta pesquisa buscou analisar os principais aspectos de uma cadeia de suprimentos específica: a cadeia de suprimentos da indústria têxtil. Para isso foi utilizada como amostra as empresas têxteis da região de Americana (SP), e que estabelecem relações de produção com fornecedores e clientes autônomos, formando assim uma cadeia de suprimentos têxtil.

Tal análise foi baseada em indicadores estruturais da cadeia, obtidos por meio da técnica de análise de rede que utiliza softwares para esse fim, sendo os principais, nesse caso, o Ucinet ${ }^{\circledast}$ e NetDraw ${ }^{\circledR}$. A partir da construção de uma matriz relacional estabelecida entre as unidades produtoras da amostra escolhida, seguido da aplicação de técnicas gráficas de modelagem baseadas em análise de redes. Assim, foi obtido o gráfico que representa a estrutura da rede e, posteriormente calculados, com o processamento dos dados no software Ucinet $^{\circledR}$, os indicadores estruturais de densidades e centralidades de grau de entrada.

Os resultados obtidos permitiram observar que a pesquisa baseada na teoria de análise de redes ajudou a entender as principais características dessa cadeia analisada, e que confirmam algumas condições da dinâmica competitiva observados em pesquisas anteriores por esse autor, como pouca cooperação e proximidade entre componentes da cadeia, aumento do grau de internacionalização de algumas empresas e do grau de heterogeneidade nas empresas componentes do aglomerado têxtil da região. Um dos indicadores 
observados é a densidade da cadeia produtiva, que ainda é baixa, o que indica a necessidade de o setor se organizar ainda mais em nível regional. Essa baixa densidade mostra também que há baixa troca de informações e recursos entre os componentes desta cadeia estudada, em que há certamente baixa influência entre os atores, conforme pesquisas realizadas anteriormente por este autor.

Por fim, a utilização das ferramentas de análise de redes por meio de softwares específicos representa um meio viável, disponível e prático para tentar entender o comportamento, a dinâmica e situação dos diversos arranjos produtivos, aglomerados, clusters e cadeias produtivas em âmbito regional e nacional, pois permite a obtenção de dados numéricos e estatísticos que servem como indicador complementar das análises destas realidades, e que, em conjunto com outras informações e pesquisas, notadamente as de cunho descritivo, servirão de subsídio para a tomada de decisões e estabelecimento de políticas de regulação e incentivo à produção e ao desenvolvimento dessas configurações produtivas. 


\title{
Characterization of supply chains: an application of companies networks concept in the textile region of Americana (SP)
}

\begin{abstract}
The Brazilian textile industry has undergone transformations in relation to its way of organizing production and marketing, especially after the commercial opening in the early 1990s. These rapid transformations have had serious consequences for this industry, such as the closure of many companies and changes in the relationships among members of the textile supply chain in various regions, such as the Textile Region of Americana (SP), one of the country's largest producer and flat fabrics. Thus, the objective of this research was to map and analyze the dynamics and characteristics of some chains in this region. This research focused on the supply chains of the textile companies in the Americana region, considering their main characteristics based on the proposed dimensions of the network analysis approach (centrality, density, intermediation and proximity). For this, a survey was conducted, based on a simple questionnaire with direct questions about the relations of the main companies with suppliers and customers. Next, the methodology of network analysis was used as a tool. The results obtained allowed to observe that the research based on the theory of network analysis helped to understand the main characteristics of this chain analyzed, and that confirm some conditions of the competitive dynamics observed in previous research by this author, as little cooperation and proximity between components of the chain, increasing the degree of internationalization of some companies and the degree of heterogeneity in the companies that make up the textile cluster in the region.
\end{abstract}

KEYWORDS: Textile Industry. Supply Chain. Business Networks 


\section{REFERÊNCIAS}

ALEJANDRO, V. A, e NORMAN, A. G. Manual introdutório de análise de redes sociais. Universidade Autônima do México (UNAM), 2005.

ARSHINDER, K. A. E DESHMUKH, S G. Supply chain coordination: perspectives, empirical studies and research directions. International Journal of Production Economics, 115(2), 316-335, 2008. crossref

BALLOU, R. H. Gerenciamento da Cadeia de Suprimentos: Planejamento, Organização e Logística Empresarial. Porto Alegre, Editora Bookman, 2010 .

BARBOSA, F. A. e SACOMANO, J. B. As redes de negócios e as cadeias de suprimentos: um estudo de caso para compreensão conceitual. Anais do XIII Encontro Nacional de Engenharia de Produção(ENEGEP), Salvador, 2001.

BORGATTI, S. P. et al.. Ucinet for Windows: Software for social network analysis. Harvard: Analytic Technologies, 2002.

BRASS, D. et al.. Taking stock of networks and organizations: a multilevel perspective. Academy of Management Journal, 47(6), 795-817, 2004. crossref

CARVALHO, J. C. Logística. Lisboa, Editora Sílabo, 1996.

CHEN, I.J., e PAULRAJ, A. Towards a theory of supply chain management: the constructs and measurements. Journal of Operations Management, 22 (2), 119-150, 2004. crossref

CHOPRA, S. e MEINDL, P. Supply chain management: strategy, planning, and operation .Pearson Prentice Hall, 2010.

CHRISTOPHER, M. Logística e gerenciamento da cadeia de suprimentos. São Paulo: Guazzelli, 1999.

COOPER, M. C., LAMBERT, D. M. e PAGH, J. D. Supply chain management: more than a new name for logistics. The International Journal of Logistics Management, vol. 8, no 1, pp.1-13, 1997. crossref 
COOPER, M. C.; ELLRAM, L. M. Characteristics of supply chain management and the implications for purchasing and logistics strategy. International Journal of Logistics Management, v. 4, n. 2, p. 13-24, 1993. crossref

CORRÊA NETO, D. A. e PIRES, S. R. I. Uma abordagem introdutória ao estudo da cadeia de suprimentos do setor têxtil brasileiro. Anais do XXIII Encontro Nacional de Engenharia de Produção (ENEGEP), Ouro Preto (MG), 2003.

CROOM, S. R.; ROMANO, P.; GIANNAKIS, M. Supply chain management: na analytical framework for critical literature review. European Journal of Purchasing \& Supply Management, Oxford, v. 6, p. 67-83, 2000. crossref

CRUZ-MOREIRA, J. R. Industrial upgrading nas cadeias produtivas globais: reflexões a partir das indústrias têxtil e do vestuário de Honduras e do Brasil. Tese de Doutoramento (Escola Politécnica da Universidade de São Paulo, Departamento de Engenharia de Produção) - Universidade de São Paulo - USP São Paulo, 2003.

DIAS, M. C. Cadeia produtiva têxtil mundial: uma abordagem a partir do conceito de cadeias produtivas globais. Revista Gestão \& Conexões. Vitória (ES), v. 3, n. 2, jul./dez. 2014. crossref

GAITHER, N. e FRAZIER, G. Administração da produção e operações. São Paulo: Pioneira Thomson Learning, 2001.

GEPFERT, A. H, Business logistics for better profit performances. Harvard Business Review, Nov.-Dez. 1968.

GEREFFI, G. et al.. Introduction: globalization, value chains and development. IDS Bulletin, v. 32, n. 3, p. 1-8, 2001. crossref

HESKETT, J. L. Logistics essential to strategy. Harvard Business Review, Nov.- Dez. 1977.

INSTITUTO BRASILEIRO DE GEOGRAFIA E ESTATÍSTICA - IBGE. Censo Demográfico 2010. Disponível em: http://www.ibge.gov.br/home/. Acesso em 20/07/2018.

JACOBS, F. R. e CHASE, R. B. Operations and supply chain management. Nova lorque, Editora McGraw-Hill Irwin, 2015. 
KNOKE, D. E KUKLINSKI, J. Network analysis. Beverly Hills, Sage Publication, 1982.

LA ROVERE, R.; HASENCLEVER, L.; MELO, L. M. Dinâmica da inovação na indústria têxtil e de confecções de Nova Friburgo - RJ. Brasília, IPEA, 2001.

LAMBERT, D. M. et al.. Administração estratégica da logística. São Paulo: Vantine Consultoria, 1998.

LAZZARINI, S. G. Empresas em rede. São Paulo, Editora Cengage Learning, 2008.

LEE, H. L. Creating value through supply chain integration. Supply Chain Management Review, Newton, MA, v.4, n.1, p.30-36, Set. 2000.

LEON, M.E. Uma Análise de Redes de Cooperação das Pequenas e Médias Empresas do Setor das Telecomunicações. Dissertação (Mestrado em Engenharia de Produção) - Universidade de São Paulo, São Paulo, 1998

LIMA FILHO et al.. Caracterização das redes de suprimento do apl de uva de mesa da região noroeste do Estado de São Paulo. Anais XLVI Congresso da Sociedade Brasileira de Economia, Administração e Sociologia Rural. Rio Branco (Ac), 2008.

LUMMUS, R R. e VOKURKA, R. J. Defining supply chain management: a historical perspective e practical guidelines. Industrial Management \& Data Systems, Wembley, Middlesex , v.99, n.1, p.11-17, 1999. crossref

LUMMUS, R.R., ALBER, K.L. Supply chain management: balancing the supply chain with customer demand. The Educational and Resource Foundation of APICS, Falls Church, VA. 1997.

MAGDALENO et al.. Estudo de ferramentas de mineração, visualização e análise de redes sociais. Rio de Janeiro, COPPE/UFRJ, 2010.

MELO, M.T., NICKEL, S. e SALDANHA-DA-GAMA, F. Facility location and supply chain management - a review. European Journal of Operational Research, 2009, vol. 196, issue 2, pages 401-412. crossref

MENTZER, J. T. et al.. Defining supply chain management. Journal of Business Logistics. v.. 22, n. 2, p. 1- 25, 2001. crossref 
MINISTÉRIO do TRABALHO e EMPREGO - MTE. Microdados RAIS e CAGED. Disponível em http://portal.mte.gov.br/geral/estatisticas.htm. Acesso em 20/07/2018.

MOYAUX, T. Approche multi-agent de la gestion des chaînes logistiques. Université Laval, Canadá, 2000.

NAPOLI, S. Diferenciação do produto: estratégia da indústria têxtil para enfrentar a concorrência estrangeira. Revista Inovação Uniemp. Campinas (SP) vol.3 no.3 Maio/Junho de 2007.

PIRES, S. R.I. Gestão da cadeia de suprimentos: conceitos, práticas e casos. São Paulo: Atlas, 2004;

QUINN, F. J. What's the buzz? Logistics Management. v. 36. 1997.

ROVAN, K. et al.. Interorganizational networks at the network level: a review of the empirical literature on whole networks. Journal of Management, Orlando, v.33, n.3, p.479-516, 2007. crossref

RIBAULT, M et al.. A gestão das tecnologias. Coleção gestão \& inovação. Lisboa, Publicações Dom Quixote, 1995.

RONQUI, R. G. et al.. Uso de softwares para análise de redes empresariais e sociais. Congresso Internacional de Administração. Ponta Grossa (PR), setembro de 2015.

SCAVARDA, L.F.R. e HAMACHER, S. Evolução da Cadeia de Suprimentos da Indústria Automobilística no Brasil. Revista de Administração Contemporânea (RAC), v. 5, n. 2, Maio/Ago. 2011: 201-219. crosssref

SHAPIRO, R. D. Get leverage from logistics. Harvard Business Review, MaioJun., 1984, pp. 119-126.

SHARMAN, G. The rediscovery of logistics. Harvard Business Review, Set.-Out. 1984, pp. 71-79.

SLACK, N. et al.. Administração da Produção (Edição Compacta). São Paulo: Atlas S.A., 2010. 
STEVENS, G. C. Integrating the supply chain. International Journal of Physical Distribution and Materials Management, v. 19, n. 8, p. 3-8. 1989. crossref

SUPPLY CHAIN COUNCIL (SCC). SCOR 9.0 Overview Booklet, 2008

TAN, K. C. A framework on supply chain management literature. European Journal of Purchasing \& Supply management. v. 7, p. 39-48, 2001. crossref

TIGRE, P. B. Gestão da inovação. São Paulo, Editora Campus, 2006.

VIANA, F. L. E; BARROS NETO, J. de P.; AÑEZ, M. E. M. Gestão da cadeia de suprimentos e vantagem competitiva relacional na indústria de calçados. Revista Produção Online, Florianópolis, v. 14, n. 4, p. 1404-1432, nov. 2014. crossref

WASSERMAN, S. e FAUST, K. Social network analysis: methods and applications. Cambridge, Cambridge University Press, 1994. crossref

DIAS, M.C. et al. Caracterização de cadeias de suprimentos: uma aplicação do conceito de redes de empresas na região têxtil de Americana (SP). R. Gest. Industr., Ponta Grossa, v. 16, n. 3, p. 194-223, Jul./Set. 2020. Disponível em: https://periodicos.utfpr.edu.br/revistagi

Correspondência:

Marcos de Carvalho Dias

Faculdade de Tecnologia (Fatec), Americana, São Paulo, Brasil.

Direito autoral: Este artigo está licenciado sob os termos da Licença Creative Commons-Atribuição 4.0 Internacional.

\section{(c) (1)}

